\title{
HISTOLOGICAL STUDY OF BLOOD VESSEL WALL FIBROSIS IN VARICOSE VEINS
}

\author{
Anjani M. Reddy', Raja Parthiban², Mohamed Hamza A33, Mohan Kumar $R^{4}$ \\ ${ }^{1}$ Associate Professor, Department of Pathology, MVJMC \& RH, Bangalore, Karnataka, India. \\ 2 Professor and HOD, Department of Pathology, MVJMC \& RH, Bangalore, Karnataka, India. \\ 3 Postgraduate Student, Department of Pathology, MVJMC \& RH, Bangalore, Karnataka, India. \\ ${ }_{4}^{4}$ Assistant Professor, Department of Surgery, MVJMC \& RH, Bangalore, Karnataka, India.
}

\begin{abstract}
BACKGROUND

Varicose veins affect around $10 \%$ of the population, various theories have been postulated about the pathophysiology of the varicose veins. Vessel wall fibrotic changes and subsequent valvular incompetence is the underlying mechanism of varicose vein pathophysiology, whether this occurs as a result of venous hypertension or as a primary change is a matter of extensive clinical research. Various genetic studies have found association with deficiency/overactivity of tissue re-modelling factors as a cause of varicose veins. Our study aims to identify the chronic inflammatory changes in the vessel wall occurring in varicose veins and identifying the primary underlying pathology.

The aim of this study was histopathological analysis of blood vessel wall fibrosis in varicose veins.
\end{abstract}

\section{MATERIALS AND METHODS}

Those patients with doppler proven saphenofemoral junction incompetence admitted in department of General Surgery in MV] Medical College and Research Hospital who are undergoing Trendelenburg's surgery satisfying the inclusion criteria were selected.

\section{RESULTS}

$62 \%$ of the subjects showed significant fibrotic changes in the vessel wall. Patients with first degree relatives who had varicose veins (71\%) showed statistically significant fibrotic changes in the vessel wall. Patients who were overweight or obese showed statistically significant fibrotic changes in the vessel wall. Co-morbidities like Hypertension, Diabetes Mellitus and CAD showed no significant association to the pathology. Addictions like alcoholism, smoking had no significant association, however tobacco chewing showed significant pathological association.

\section{CONCLUSION}

Chronic inflammation of the vessel wall in varicose veins can cause valvular incompetence. Extensive clinical study with assessment of genetic markers and tissue remodelling factors is required to establish the aetiology as an epiphenomenon.

\section{KEY WORDS}

Varicose Vein, Vessel Wall, Fibrosis.

HOW TO CITE THIS ARTICLE: Reddy AM, Parthiban R, Hamza MA, et al. Histological study of blood vessel wall fibrosis in varicose veins. J. Evolution Med. Dent. Sci. 2019;8(09):547-550, DOI: 10.14260/jemds/2019/121

\section{BACKGROUND}

Varicose veins are a common medical condition present in at least $8-10 \%$ of the general population. The findings of varicose veins may include dilated and tortuous veins, telangiectasias and fine reticular varicosities. Risk factors for varicose veins include family history, female sex, obesity, inactivity. Varicose veins can be classified as primary or secondary. Primary varicose veins result from intrinsic abnormalities of the venous wall, whereas secondary varicose veins are associated with deep and/or superficial venous insufficiency.

In addition to noting the unsightly appearance, patients with varicose veins may complain of aching, heaviness, pruritus, and early fatigue of the affected leg.

'Financial or Other Competing Interest': None.

Submission 08-01-2019, Peer Review 18-02-2019,

Acceptance 22-02-2019, Published 04-03-2019.

Corresponding Author:

Dr. Anjani M. Reddy,

No. 1495, $26^{\text {th }}$ Cross, $26^{\text {th }}$ Main,

HSR Layout, Sector 2, Bangalore-560102,

Karnataka, India

E-mail: doctoranjanireddy@gmail.com

DOI: $10.14260 /$ jemds $/ 2019 / 121$
These symptoms worsen with prolonged standing and sitting and are relieved by elevation of the leg above the level of the heart. A mild amount of oedema is often present. More severe signs include thrombophlebitis, hyperpigmentation, lipodermatosclerosis, ulceration and bleeding from attenuated vein clusters.

Risk factors for the development of varicose veins include advancing age, female gender, heredity and history of trauma to the extremity.

Pertubations in haemodynamic forces in the vein wall influence cytoskeletal organization, gene expression, proliferation and survival may induce inflammation and the subsequent remodelling of the wall and venous valves. All these are fundamental mechanisms that underlie various pathogenesis implicated in varicose veins formation.

All patients with varicose veins should undergo an assessment by duplex scan. There is some evidence that this policy leads to a more accurate surgical approach and reduces the incidence of recurrence of the varicose veins.

An important component of treatment for patients with varicose veins is the use of elastic compression stockings. Patients may be prescribed elastic stockings with compression ranging from 20 to 30,30 to 40 , or even 40 to 50 $\mathrm{mmHg}$. Stockings range in length from knee high to waist 
high, and they should be able to cover the symptomatic varices. The majority of patients may be managed without additional therapy.

Additional interventions are warranted in patients whose symptoms worsen or are unrelieved despite compression therapy or who have signs of lipodermatosclerosis. Cosmetic concerns also often lead to intervention.

The pathophysiology of varicose veins development is probably related to defective connective tissue and smooth muscle in the vein wall leading to a secondary incompetence of the valves rather than to primary defect in the valves, which occurs in a small group of patients who have total venous avalvulosis.

So, in this study patients with varicose veins who have sapheno-femoral incompetence and willing to get operated in our hospital will be explained about the various surgical options, and those patients who are planned for saphenofemoral flush ligation and willing to take part in the study will be included in the study. In these patients after flush ligation the venous segment will be sent for histopathological analysis and the results will be compared with that of various studies.

\section{Aim of The Study}

Histopathological study of blood vessel wall fibrosis in varicose veins.

\section{MATERIALS AND METHODS}

\section{Source of Data}

Registered subjects registered in surgery Department of Pathology MVJ Medical College, Bangalore, with diagnosis of varicose veins with saphenofemoral incompetence (Clinically as well as colour doppler study) will be taken up for the study. Primary source of information technique will be used as the source of information with "Informed written consent" method for the subject's consent.

\section{Sample Size}

Sample size was taken as convenience.

\section{Design of Study}

Descriptive study.

\section{Inclusion Criteria}

Late adolescents and adult subjects admitted to surgical wards of MVJ Medical College, Bangalore with diagnosis of varicose veins with saphenofemoral incompetence (Clinically as well as colour- doppler study).

\section{Exclusion Criteria}

Nil.

\section{Method of Collection of Data}

Patients presenting to Surgery Op with symptoms of varicose veins will be examined clinically. Diagnostic investigations (colour Doppler) will be carried out. Those patients who requires Surgery will be explained about the various surgical options, and those patients who are planned for saphenofemoral flush ligation and willing to take part lathe study will be included in the study. In these patients after flush ligation the venous segment will be done at pathology department for histopathological analysis, thin cut sections will be stained with Haematoxylin and Eosin stain and assessed for vessel wall inflammation and fibrosis, and the results will be compared with that of various studies.

\section{Statistical Techniques}

Proportions, Chi-square test, Bar chart, Pie -chart, co-efficient of ontigency and related statistics will be used and data will be analysed with the help of suitable statistical software.

\section{Study Period}

34 months.

\section{Study Setting}

Surgery OP, Wards, Pathology department MVJ Medical College, Bangalore.

\section{RESULTS}

Our study was conducted on 22 subjects admitted at MVJ MC\&RH with Doppler proven saphenofemoral incompetence for Trendelenburg operation.

\begin{tabular}{|c|c|c|}
\hline Histopathology Report & Frequency & Percent \\
\hline No Fibrosis & 3 & 12 \\
\hline Mild & 6 & 24 \\
\hline Moderate & 9 & 36 \\
\hline Severe & 7 & 28 \\
\hline Total & $\mathbf{2 5}$ & $\mathbf{1 0 0}$ \\
\hline \multicolumn{2}{|c|}{ Table 1. Vessel Wall Histopathology } \\
\hline
\end{tabular}

\begin{tabular}{|c|c|c|c|c|c|c|}
\hline \multirow{2}{*}{ AGE } & \multicolumn{4}{|c|}{ Pathology } & \multicolumn{2}{c|}{ Total } \\
\cline { 2 - 7 } & \multicolumn{2}{|c|}{ Mild } & \multicolumn{2}{|c|}{ Moderate/Severe } & N & \% \\
\cline { 2 - 7 } & $\mathbf{N}$ & $\mathbf{\%}$ & $\mathbf{N}$ & $\mathbf{\%}$ & & \\
\hline $20-30$ & 1 & 4 & 0 & 0 & 1 & 4 \\
\hline $31-40$ & 1 & 4 & 1 & 4 & 2 & 8 \\
\hline $41-50$ & 2 & 8 & 8 & 32 & 10 & 40 \\
\hline $51-60$ & 2 & 8 & 5 & 20 & 7 & 28 \\
\hline $61-70$ & 1 & 4 & 3 & 12 & 4 & 16 \\
\hline$>70$ & 1 & 4 & 0 & 0 & 1 & 4 \\
\hline Total & $\mathbf{8}$ & $\mathbf{3 2}$ & $\mathbf{1 7}$ & $\mathbf{6 8}$ & $\mathbf{2 5}$ & $\mathbf{1 0 0}$ \\
\hline
\end{tabular}

Table 2. Interpretation Changes Between Age and Vessel Wall Fibrosis

\begin{tabular}{|c|c|c|c|c|c|c|}
\hline \multirow{2}{*}{ Gender } & \multicolumn{4}{|c|}{ Pathology } & \multicolumn{2}{c|}{ Total } \\
\cline { 2 - 5 } & \multicolumn{2}{|c|}{ Mild } & Moderate/Severe & \multirow{2}{*}{$\mathbf{N}$} & $\mathbf{\%}$ \\
\cline { 2 - 5 } \cline { 3 - 4 } & $\mathbf{N}$ & $\mathbf{\%}$ & $\mathbf{N}$ & $\mathbf{\%}$ & & \\
\hline Male & 5 & 20 & 8 & 28 & 13 & 52 \\
\hline Female & 4 & 16 & 8 & 36 & 12 & 48 \\
\hline Total & $\mathbf{9}$ & $\mathbf{3 6}$ & $\mathbf{1 6}$ & $\mathbf{6 4}$ & $\mathbf{2 5}$ & $\mathbf{1 0 0}$ \\
\hline Table 3. Association Between Gender and Vessel Wall \\
Fibrosis \\
\hline
\end{tabular}

\begin{tabular}{|c|c|c|c|c|c|c|}
\hline \multirow{2}{*}{$\begin{array}{c}\text { Family } \\
\text { History }\end{array}$} & \multicolumn{3}{|c|}{ Pathology } & \multicolumn{2}{c|}{ Total } \\
\cline { 2 - 7 } & $\mathbf{N}$ & $\mathbf{\%}$ & $\mathbf{N}$ & $\mathbf{\%}$ & & \\
\hline No & 5 & 20 & 6 & 24 & 11 & 44 \\
\hline Yes & 3 & 12 & 11 & 44 & 14 & 56 \\
\hline Total & $\mathbf{8}$ & $\mathbf{3 2}$ & $\mathbf{1 7}$ & $\mathbf{6 8}$ & $\mathbf{2 5}$ & $\mathbf{1 0 0}$ \\
\hline Table 4. Association Between Family History Of Varicose \\
Vein And Vessel Wall Fibrosis \\
\hline
\end{tabular}




\begin{tabular}{|c|c|c|c|c|c|c|}
\hline \multirow{2}{*}{ Hypertension } & \multicolumn{4}{|c|}{ Pathology } & \multicolumn{2}{c|}{ Total } \\
\cline { 2 - 7 } & \multicolumn{2}{|c|}{ Mild } & \multicolumn{2}{|c|}{ Moderate/Severe } & N & $\mathbf{\%}$ \\
\cline { 2 - 7 } & $\mathbf{N}$ & $\mathbf{\%}$ & $\mathbf{N}$ & $\mathbf{\%}$ & & \\
\hline No & 4 & 16 & 6 & 24 & 10 & 40 \\
\hline Yes & 3 & 12 & 12 & 48 & 15 & 60 \\
\hline Total & $\mathbf{7}$ & $\mathbf{2 8}$ & $\mathbf{1 8}$ & $\mathbf{7 2}$ & $\mathbf{2 5}$ & $\mathbf{1 0 0}$ \\
\hline
\end{tabular}

Table 5. Association Between Vessel Wall Fibrosis and Hypertension

\begin{tabular}{|c|c|c|c|c|c|c|}
\hline \multirow{2}{*}{$\begin{array}{c}\text { Diabetes } \\
\text { Mellitus }\end{array}$} & \multicolumn{4}{|c|}{ Pathology } & \multicolumn{2}{|c|}{ Total } \\
\cline { 2 - 5 } & \multicolumn{2}{|c|}{ Mild } & Moderate/Severe & \multirow{2}{*}{$\mathbf{N}$} & $\%$ \\
\hline No & 8 & 32 & 11 & 44 & 19 & 76 \\
\hline Yes & 1 & 04 & 5 & 20 & 6 & 24 \\
\hline Total & $\mathbf{9}$ & $\mathbf{3 6}$ & $\mathbf{1 6}$ & $\mathbf{6 4}$ & $\mathbf{2 5}$ & $\mathbf{1 0 0}$ \\
\hline Table 6. Association Between Vessel Wall Fibrosis and \\
Diabetes Mellitus \\
\hline
\end{tabular}

\begin{tabular}{|c|c|c|c|c|c|c|}
\hline \multirow{3}{*}{ CAD } & \multicolumn{4}{|c|}{ Pathology } & \multicolumn{2}{c|}{ Total } \\
\cline { 2 - 7 } & \multicolumn{2}{|c|}{ Mild } & \multicolumn{2}{|c|}{ Moderate/Severe } & N & $\mathbf{\%}$ \\
\cline { 2 - 7 } & $\mathbf{N}$ & $\mathbf{\%}$ & $\mathbf{N}$ & $\mathbf{\%}$ & & \\
\hline No & 8 & 32 & 13 & 52 & 21 & 84 \\
\hline Yes & 1 & 4 & 3 & 12 & 04 & 16 \\
\hline Total & $\mathbf{8}$ & $\mathbf{3 6}$ & $\mathbf{1 7}$ & $\mathbf{6 4}$ & $\mathbf{2 5}$ & $\mathbf{1 0 0}$ \\
\hline
\end{tabular}

Table 7. Association Between Vessel Wall Fibrosis And Coronary Artery Disease

\begin{tabular}{|c|c|c|c|c|c|c|}
\hline \multirow{2}{*}{ Smoking } & \multicolumn{4}{|c|}{ Pathology } & \multicolumn{2}{c|}{ Total } \\
\cline { 2 - 7 } & \multicolumn{2}{|c|}{ Mild } & \multicolumn{2}{c|}{ Moderate/Severe } & N & $\%$ \\
\cline { 2 - 7 } & $\mathbf{N}$ & $\mathbf{\%}$ & $\mathbf{N}$ & $\mathbf{\%}$ & & \\
\hline No & 5 & 20 & 13 & 52 & 18 & 72 \\
\hline Yes & 1 & 4 & 6 & 24 & 7 & 28 \\
\hline Total & $\mathbf{6}$ & $\mathbf{2 4}$ & $\mathbf{1 9}$ & $\mathbf{7 6}$ & $\mathbf{2 5}$ & $\mathbf{1 0 0}$ \\
\hline Table 8. Association Between Vessel Wall Fibrosis and \\
Smoking \\
\hline
\end{tabular}

\begin{tabular}{|c|c|c|c|c|c|c|}
\hline \multirow{2}{*}{$\begin{array}{c}\text { Pan - } \\
\text { Chewing }\end{array}$} & \multicolumn{4}{|c|}{ Pathology } & \multicolumn{2}{c|}{ Total } \\
\cline { 2 - 6 } & $\mathbf{2}$ & $\mathbf{\%}$ & $\mathbf{N}$ & $\mathbf{\%}$ & & \multirow{2}{*}{$\%$} \\
\hline No & 19 & 76 & 3 & 12 & 22 & 88 \\
\hline Yes & 2 & 8 & 1 & 4 & 03 & 12 \\
\hline Total & $\mathbf{2 1}$ & $\mathbf{8 4}$ & $\mathbf{4}$ & $\mathbf{1 6}$ & $\mathbf{2 5}$ & $\mathbf{1 0 0}$ \\
\hline
\end{tabular}

Table 9. Interpretation Changes Between Vessel Wall Fibrosis and Pan Chewing

\begin{tabular}{|c|c|c|c|c|c|c|}
\hline \multirow{2}{*}{ BMI } & \multicolumn{4}{|c|}{ Pathology } & \multicolumn{2}{c|}{ Total } \\
\cline { 2 - 7 } & \multicolumn{2}{|c|}{ Mild } & \multicolumn{2}{|c|}{ Moderate/Severe } & N & $\mathbf{\%}$ \\
\cline { 2 - 7 } & $\mathbf{N}$ & $\mathbf{\%}$ & $\mathbf{N}$ & $\mathbf{\%}$ & & \\
\hline Normal & 8 & 32 & 5 & 20 & 13 & 52 \\
\hline $\begin{array}{c}\text { Over } \\
\text { Weight }\end{array}$ & 2 & 8 & 7 & 28 & 9 & 36 \\
\hline Obese & 1 & 4 & 2 & 8 & 3 & 12 \\
\hline Total & $\mathbf{1 1}$ & $\mathbf{4 4}$ & $\mathbf{1 4}$ & $\mathbf{5 6}$ & $\mathbf{2 5}$ & $\mathbf{1 0 0}$ \\
\hline Table 10. Association Between Vessel Wall Fibrosis And \\
BMI
\end{tabular}

\section{DISCUSSION}

Our study on chronic vessel wall inflammation and fibrosis was done on 100 subjects admitted in MVJ Medical College, who were diagnosed with Doppler proven saphenofemoral junction in planned for elective Trendelenburg operation. The vein samples for the pathological analysis were obtained from saphenofemoral junction ligation samples and were sent to the Department of Pathology, for analysis to look for evidence of fibrosis and collagen deposition, using Haematoxylin and
Eosin stain. The pathological analysis described the vessel wall as having no fibrosis, mild, moderate, severe fibrosis.

Our study considered mild, moderate and severe fibrosis as significant and also analysed the association of moderate/severe fibrosis to various co- morbidities like diabetes, hypertension, coronary artery disease, obesity and cigarette smoking, family history of varicose veins (Any first degree relative with varicose veins)

The histopathological analysis showed that of the samples sent, $12 \%$ of subjects had no fibrosis, $24 \%$ had mild fibrosis, $36 \%$ moderate fibrosis and remaining $28 \%$ had severe fibrosis.

Among 25 subjects 8 (28\%) males and 8 (36\%) females had moderate/severe fibrosis. But there is no statistically significant association between gender and severity of fibrosis from our study.

Javien's study ${ }^{1}$ showed that varicose veins were more common in women, but female sex was not found to be a strong risk factor. The incidence of varicose veins is higher among women than men. Compared to women without varicose veins, women with varicose veins were more often obese, low levels of physical activity and higher systolic blood pressure, and were older at menopause.

Majority of subjects were in the age group 41-50 years (40\%, n 10). Among this group, 8(32\%) had moderate/severe fibrosis and remaining $2(8 \%)$ had mild fibrosis various studies have shown that the prevalence of varicose veins increases with age.

The Edinburgh vein study found a significant increase in prevalence from $11.5 \%$ in individuals aged 18 to 24 years to $55.7 \%$ in the age range 55 to 64 years.(2)

14 out of $25(56 \%)$ had a family history of varicose veins. Among those with positive family history, 11 (44\%) had moderate/severe fibrosis.

Hirai et al(3) reported a positive family history in $42 \%$ of Japanese patients with varicose veins compared with $14 \%$ in patients without a family history of varicose veins.

The Framingham study demonstrated a prevalence of $1 \%$ in men versus $10 \%$ in women $<30$ years of ge compared with $57 \%$ and $77 \%$ in men and women over the age of 70 years respectively. The Framingham study, found an annual incidence of varicose vein of $2.6 \%$ in women and $1.9 \%$ in men. (4)

In a population-based study, Carpentier et al found that a history of varicose veins in first-degree relatives and age were among the two most important risk factors for varicose veins in both sexes. (5)

Among 25 subjects, 9 (36\%) were overweight and 3 (12\%) were obese. Majority (52\%, n-13) had a normal BMI. Two $(8 \%)$ subjects with obesity had moderate/severe fibrosis. Among 9 overweight subjects, 7(28\%) had moderate/severe fibrosis. Among 13 (52\%) subjects with normal BMI, 8(32\%) had mild fibrosis.

$15(60 \%)$ were hypertensive, of which $12(48 \%)$ had moderate/severe fibrosis while 3 (12\%) of them had mild fibrosis. 3 subjects (12\%) had pan-chewing habits and only one patient had moderate/severe fibrosis (4\%),

7 subjects $(28 \%)$ were smokers, of which $6(24 \%)$ had moderate/severe fibrosis. 6 (24\%) had diabetes of which 5 (20\%) had moderate/severe fibrosis, 4 (16\%) had coronary artery disease of which $3(12 \%)$ had moderate/severe fibrosis. 


\section{CONCLUSION}

1. Varicose Veins occur as a result of the fibrotic changes due to the chronic inflammatory changes in the vessel wall which may lead to valvular incompetence.(7)

2. In our study, $64 \%$ of the subjects showed significant fibrotic changes in the vessel wall

3. Patients in the age group 41-50 years showed moderate to severe vessel wall fibrosis (32\%)

4. Patients with first degree relatives who had varicose veins (44\%) showed significant fibrotic changes in the vessel wall.

5. Patients who were overweight or obese, hypertensive, showed moderate to severe fibrotic changes in the vessel wall.

6. Pan chewing habits, smoking, diabetes mellitus and coronary artery disease showed no significant association with the pathology.

\section{REFERENCES}

[1] Jawien A. The influence of environmental factors in chronic venous insufficiency. Angiology 2003;54(Suppl 1):S19-S31.
[2] Ruckley CV, Evans CJ, Allan PL, et al. Chronic venous insufficiency: clinical and duplex correlations. The Edinburgh Vein Study of venous disorders in the general population. J Vasc Surg 2002;36(3):520-5.

[3] Hirai M, Naiki K, Nakayama R. Prevalence and risk factors of varicose veins in Japanese women. Angiology 1990;41(3):228-32.

[4] Brand FN, Dannenberg AL, Abbott RD, et al. The epidemiology of varicose veins: the Framingham Study. Am J Prev Med 1988;4(2):96-101.

[5] Carpentier PH. Epidemiology and physiopathology of chronic venous leg diseases. Rev Prat 2000;50(11):1176-81.

[6] Kroeger K, Ose C, Rudofsky G, et al. Risk factors for varicose veins. Int Angiol 2004;23(1):29-34.

[7] Raffetto JD, Khalil RA. Mechanisms of varicose vein formation: valve dysfunction and wall dilation. Phlebology 2008;23(2):85-98. 